\title{
Sistem Otomasi Perpustakaan dengan Barcode SLTPI Al Azhar 8, Kemang Pratama
}

\author{
Endang Ripmiatin*, Riani Aliviani \\ Program Studi Teknik Informatika, Fakultas Sains dan Teknologi, \\ Universitas Al Alzhar Indonesia, Jl. Sisingamangaraja, Jakarta 12110 \\ *Penulis untuk Korespondensi: endang_nizar@uai.ac.id
}

\begin{abstract}
Abstrak - Kesadaran orang akan pentingnya layanan prima yang nyaman bagi pelanggan, menuntut tersedianya sistem yang efisien dan handal. Perpustakaan SLTPI Al Azhar 8 sangat menyadari pentingnya sistem yang dapat meningkatkan kinerja karyawannya dengan cara meningkatkan efisiensi dan meminimalkan kerja manual untuk menghindari kesalahan manusia. Dalam penelitian ini, sistem perpustakaan dirancang dengan menggunakan barcode scanner sebagai alat bantu input data, untuk dapat mempercepat kerja layanan dan meningkatkan akurasi data. Sistem Perpustakaan ini dirancang sesuai dengan proses bisnis yang ada dengan dilengkapi beberapa fitur baru yang teridentifikasi dalam tahap analisa kebutuhan seperti pengecekan terhadap resources yang dimasukkan, perpindahan data antar pengguna dilakukan melalui sistem, sehingga dapat meningkatkan efisiensi proses bisnis yang berjalan saat ini.
\end{abstract}

Abstract - Recently people starts to realize the importance of service excellence and demand an efficient and reliable system. SLTPI Al Azhar 8 Library awares of the needs of new system to improve its performance through maximizing staffs performance and minimizing manual operations to prevent human error. In this research, library system was designed to use barcode scanner as input tool, to shorten the service and increase data accuracy. This system was designed to fit the existing business process with additional features identified in the user requirement analysis stage, such as resource checking, automatic data transfer, to improve the existing business process.

Keywords - Barcode, UML, VB.NET, SQL Server

\section{PENDAHULUAN}

$\mathrm{P}$ erpustakaan sekolah yang terletak di lingkungan SLTPI Al Azhar 8 Kemang Pratama, Bekasi adalah perpustakaan yang disediakan untuk siswa agar dapat menunjang sistem pembelajaran yang ada di sekolah maupun pengetahuan umum yang lainnya. Perpustakaan ini terbilang masih baru, sehubungan dengan pemindahan gedung SLTPI Al Azhar 8 Kemang Pratama. Pada awalnya siswa tidak banyak yang meminjam buku di perpustakaan ini, sehingga petugas perpustakaan masih dapat menangani aktivitas perpustakaan seperti pendataan buku, peminjaman buku, pengembalian buku dan lain-lain secara manual. Namun pada akhir-akhir ini petugas perpustakaan di sekolah ini mulai mengalami kesulitan karena meningkatkan permintaan peminjaman buku dan banyaknya penambahan koleksi buku.

Layanan perpustakaan yang masih bersifat manual menimbulkan berbagai kendala dalam pemberian layanan, misalnya: petugas perpustakaan dalam memberikan layanan sirkulasi harus mencatat data buku yang dipinjam secara manual ke kartu perpustakaan dan kartu kontrol perpustakaan, sehingga layanan menjadi lambat karena memerlukan waktu yang cukup lama. Selain itu siswa yang ingin meminjam buku seringkali mengalami kesulitan, karena harus mengecek sendiri ke tiap rak untuk memperoleh buku yang mereka inginkan. Saat ini informasi dan data tentang buku hanya dicatat dalam buku besar perpustakaan, sehingga pemutakhiran data koleksi buku memerlukan waktu relatif lama dan tidak akurat. Uraian di atas memberikan gambaran bahwa sistem manual yang ada sekarang ini tidak memberikan akses yang optimal dalam pengelolaan koleksi buku dan layanan kepada siswa. 
Salah satu fitur yang dikembangkan dalam sistem perpustakaan adalah pemanfaatan teknologi barcode untuk memberi kemudahan kepada petugas dalam pemberian layanan kepada siswa, misalnya scanning ID buku, scanning ID anggota, sehingga kendala-kendala dalam memberikan layanan kepada siswa dapat diminimalkan. Sistem informasi layanan perpustakaan berbasis teknologi barcode dipilih menjadi alternatif pemberian layanan.

\section{TINJAUAN PUSTAKA}

Penggunaan teknologi untuk pengelolaan barang inventori sudah merupakan kecenderungan yang tidak dapat dihindarkan untuk modernisasi pengelolaan produk dan barang [1]. Barcode sudah menjadi bagian dari produk yang kita beli dan sudah menjadi standar untuk identifikasi dan pelacakan produk. Menurut survei yang dilaksanakan oleh Zebra Technologies di tahun 2006, lebih dari 96\% perusahaan di Eropa mengalami peningkatan efisiensi dengan penggunaan barcode. Alasan lain yang mendasari berbagai perusahaan di Eropa menggunakan barcode adalah penigkatan akurasi dalam proses pemesanan dan penagihan invoice (32\%), penurunan biaya (26\%), dan fakta bahwa belum tersedianya teknologi yang lebih baru (16\%) [2].

Teknologi barcode sebaiknya tidak ditentukan sebagai solusi, sebelum target organisasi ditentukan. Target yang umum dalam pemanfaatan teknologi ini adalah penurunan kesalahan (human error), data akurat untuk pengendalian inventori, perbaikan mutu layanan bagi konsumen, dll [3].

Objek utama yang menjadi fokus dalam penelitian ini adalah barcode 1 dimensi. Barcode ini dinamakan 1 dimensi atau ada yang menyebut sebagai linear barcodes karena kodenya hanya terdiri dari baris-baris. Terdapat banyak jenis barcode 1 dimensi yang bisa dilihat dalam Tabel 1 .

Jenis barcode 1 dimensi yang digunakan dalam penelitian ini adalah barcode yang dikeluarkan oleh sistem European Article Numbering (EAN), yaitu EAN-8 dan EAN-13, barcode standar internasioinal untuk menandai kemasan produk barang atau makanan retail.

Standarisasi EAN-13 menggunakan 13 digit kode di mana 3 digit pertama untuk kode negara asal produk, 4 digit berikutnya adalah kode pabrik (manufacturer), 5 digit berikutnya adalah kode produk dan 1 digit terakhir adalah check digit atau angka untuk melakukan test validasi barcode dengan algoritma tertentu.

Tabel 1. Barcode Tipe 1 Dimensi

\begin{tabular}{|c|c|}
\hline Simbologi & Pengguna \\
\hline U.P.C & Worldwide retail \\
\hline Codabar & $\begin{array}{l}\text { Old format used in } \\
\text { libraries, blood banks } \\
\text { airbills }\end{array}$ \\
\hline $\begin{array}{l}\text { Code } 25 \text { - Non Interleaved } \\
2 \text { of } 5\end{array}$ & Industrial (NO) \\
\hline $\begin{array}{l}\text { Code } 25 \text { - Interleaved } 2 \text { of } \\
5\end{array}$ & $\begin{array}{l}\text { Wholeshale, Libraries } \\
\text { (NO) }\end{array}$ \\
\hline Code 39 & Various \\
\hline Code 93 & Various \\
\hline Code 128 & Various \\
\hline Code 11 & Telephone \\
\hline CPC Binary & Post Office \\
\hline DUN 14 & Various \\
\hline EAN 2 & Addon code (magazines) \\
\hline EAN 5 & Addon code (books) \\
\hline EAN 8, EAN 13 & Worldwide retail \\
\hline ITF-14 & $\begin{array}{l}\text { Non retail packaging } \\
\text { levels }\end{array}$ \\
\hline Latent Image Barcode & Color Print Film \\
\hline Pharmacode & Pharmaceutical Packaging \\
\hline Plessey & $\begin{array}{l}\text { Catalogs, storeshelves, } \\
\text { inventory }\end{array}$ \\
\hline PLANET & $\begin{array}{l}\text { United States Postal } \\
\text { Service }\end{array}$ \\
\hline POSTNET & $\begin{array}{l}\text { United States Postal } \\
\text { Service }\end{array}$ \\
\hline Intelligent Mail Barcode & $\begin{array}{l}\text { United States Postal } \\
\text { Service }\end{array}$ \\
\hline MSI & $\begin{array}{l}\text { Used for warehouse } \\
\text { shelves and inventory }\end{array}$ \\
\hline RM4SCC/KIX & $\begin{array}{l}\text { Royal Mail / Royal TPG } \\
\text { Post }\end{array}$ \\
\hline
\end{tabular}

Kode EAN-13 banyak digunakan di Indonesia untuk indentifikasi produk nasional. Indonesia sendiri mempunyai kode 899 untuk 3 digit pertama [4].

Kode EAN 8 merupakan subset dari kode EAN-13, diperkenalkan untuk kemasan makanan yang kecil di mana barcode EAN-13 menjadi terlalu besar, misalnya untuk kemasan rokok atau permen. Standarisasi EAN menggunakan 8 digit, yaitu 2 digit kode negara, 5 digit data dan 1 digit check digit. 


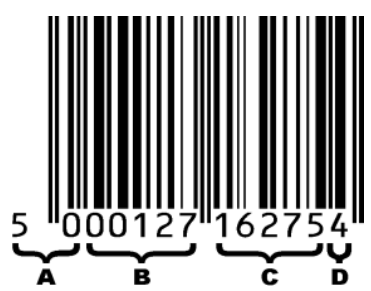

Gambar 1. EAN 13 [2]

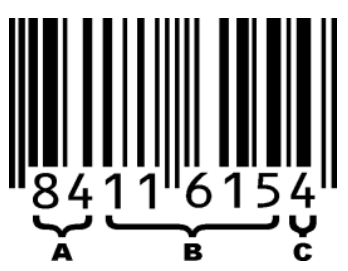

Gambar 2. EAN 8 [2]

\section{METODE PENELITIAN}

\subsection{Studi Lapangan}

Penelitian dilakukan langsung di Perpustakaan SLTPI Al Azhar 8, Kemang Pratama. Observasi dilaksanakan dengan mengikuti cara kerja petugas perpustakaan untuk mendapatkan gambaran mengenai proses bisnis saat ini; dilengkapi wawancara dengan Kepala Perpustakaan untuk mendapatkan gambaran kebutuhan dan harapan akan sistem ke depannya.

\subsection{Analisa dan Perancangan}

Dalam tahap analisa dan perancangan digunakan Unified Modeling Language (UML) dengan memanfaat use case diagram untuk menggambarkan fungsi-fungsi yang dibutuhkan; use case narrative untuk merancang interaksi pengguna-sistem agar setiap rincian kebutuhan dapat teridentifikasi. Statechart diagram digunakan untuk menggambarkan perubahan status buku dalam proses sirkulasi koleksi [5] [6].

\subsection{Pengembangan Sistem}

Sistem ini dikembangkan mengikuti metode System Development Life Cycle (SDLC) dengan menggunakan bahasa pemrograman Visual Basic.NET (VB.NET) dan sistem basis data SQL Server database.

\section{HASIL DAN PEMBAHASAN}

\subsection{Proses Bisnis Saat Ini}

Perpustakaan SLTPI AL AZHAR 8 Kemang Pratama masih menggunakan cara manual untuk mencatat transaksi yang terjadi di perpustakaan, baik peminjaman, pengembalian, penghitungan denda maupun pendataan koleksi yang ada di dalam perpustakaan tersebut.
Dalam proses bisnisnya, setiap kali siswa datang ke meja Petugas Perpustakaan untuk meminjam buku, maka petugas secara manual menuliskan data buku yang dipinjam (kode dan judul buku) ke dalam file excel, yang tentunya membutuhkan cukup banyak waktu sehingga dapat menimbulkan antrian yang cukup panjang.

Data koleksi diinput dan disimpan ke dalam sebuah berkas excel yang terpisah, yang tidak dapat dijamin akurasi dan kemutakhirannya karena sangat tergantung tingkat kedisiplinan petugas.

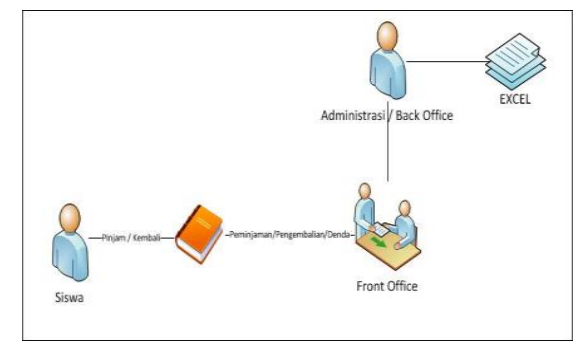

Gambar 3. Proses Bisnis Perpustakaan Saat Ini

\subsection{Proses Bisnis yang Dituju}

Sistem baru dirancang untuk menyederhanakan proses bisnis dengan cara memanfaatkan teknologi barcode. Barcode digunakan untuk mempercepat proses pencatatan kegiatan peminjaman dan pengembalian koleksi. Alat ini juga meminimalkan kesalahan penulisan kode koleksi, baik buku ataupun media.

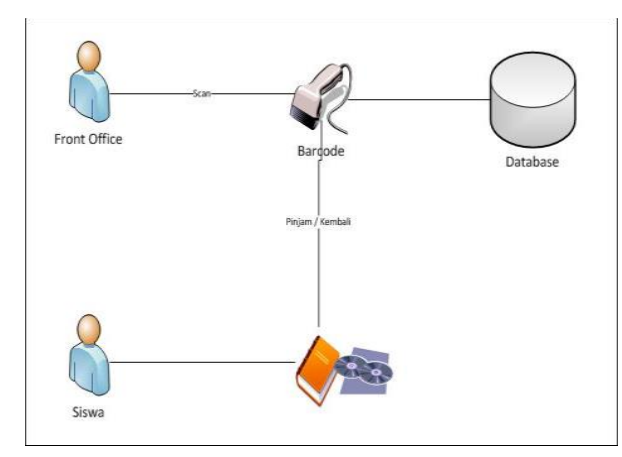

Gambar 4. Proses Bisnis Yang Dituju

Pada Gambar 4 terlihat bahwa dengan adanya barcode scanner petugas Perpustakaan tidak perlu mencatat transaksi secara manual, cukup melakukan scan pada koleksi yang dipinjam/ dikembalikan, dan data langsung dikelola dalam sistem basis data. 
sehingga dapat meminimalkan tingkat kesalahan manusia.

Dengan adanya sistem basis data menggantikan MS Excel, keamanan data dapat ditingkatkan dan pengelolaan data koleksi menjadi lebih mudah.

\subsection{Cara Kerja Barcode}

Proses penggunaan barcode pada aplikasi Sistem Otomasi Perpustakaan dengan Barcode di SLTPI Al Azhar 8 Kemang Pratama dimulai dengan pembuatan label pada buku dan media yang ada di perpustakaan dengan langkah-langkah berikut:

1. Petugas Perpustakaan terlebih dahulu menentukan kode pada masing-masing buku. Seperti kode klasifikasi, kode sekolah, kode buku, kode rak dan kode cek buku.

2. Petugas Perpustakaan menginput kode yang telah ditentukan pada masing-masing buku ke sistem.

3. Sistem mengubah angka-angka yang diinputkan menjadi batangan barcode dalam bentuk gambar.

4. Gambar barcode yang sudah ada di cetak ke kertas stiker yang telah disediakan

5. Setelah barcode tercetak Petugas Perpustakaan menempelkan hasilnya ke setiap buku.

Setelah semua buku diberikan label pada Petugas Perpustakaan maka informasi terhadap buku tersebut dapat dimasukan ke dalam sistem sehingga kinerja dari Petugas Perpustakaan menjadi lebih efisien.

Dalam pembuatan label ini tipe data barcode yang digunakan yaitu EAN 8 dan EAN 13. Sebagai contoh:

- Judul: Belajar Visual Basic 2010

- Kode Perpustakaan:

$$
\begin{aligned}
& \text { 1-2 Digit }=\text { Kode Sekolah } \\
& \text { 3-5 Digit }=\text { Kode Klasifikasi } \\
& \text { 6-9 Digit }=\text { Kode Buku/Nomer Urut } \\
& \text { 10-12 Digit }=\text { Kode Rak Buku } \\
& \text { 13 Digit }=\text { Cek Digit }
\end{aligned}
$$

Dikarenakan pembuatan label mengikuti aturan kode perpustakaan diatas maka label barcode yang dihasilkan menjadi 0200003014231

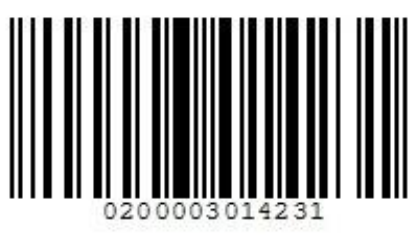

Gambar 5. Contoh Barcode Label pada Buku

\subsection{Use Case Diagram}

Use Case Sistem Admin ini menggambarkan cara kerja Admin yang bertanggung jawab menangani member secara langsung.

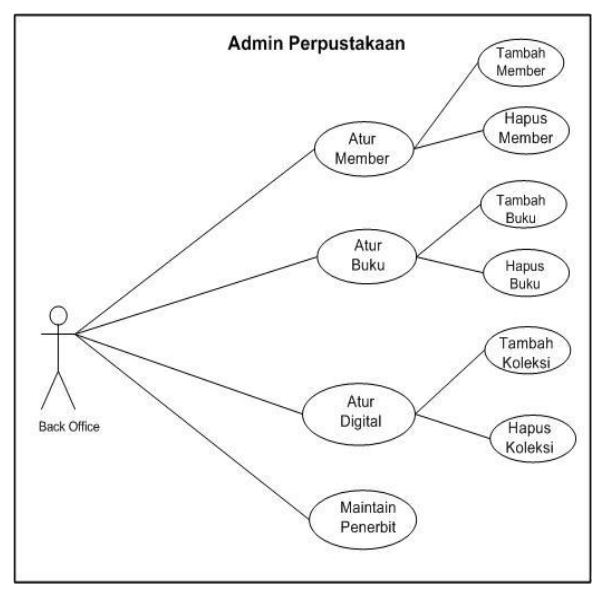

Gambar 6. Use Case Diagram

\subsection{Statechart Diagram}

Gambar 7 menunjukkan bahwa dalam proses pengembalian, terdapat perubahan status pinjaman. Bila tanggal pengembalian lebih besar dari tanggal yang sudah ditentukan sebelumnya maka sistem akan mendeteksi bahwa status pinjaman ini harus dikenakan denda.

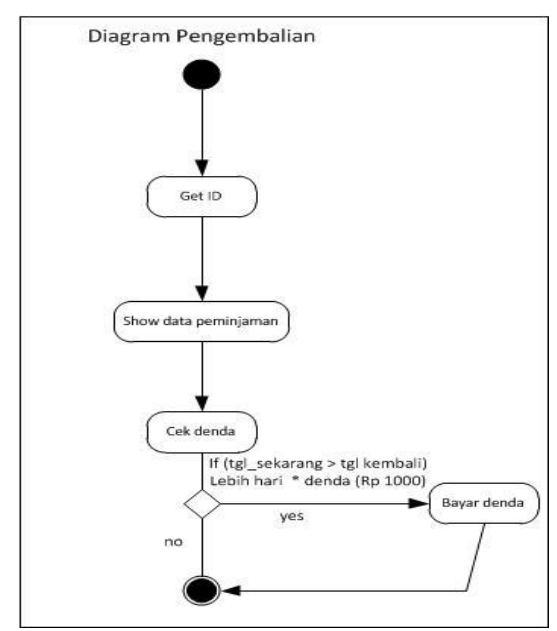

Gambar 7. Statechart Diagram Pengembalian 


\subsection{Pengembangan Sistem}

Menu Utama yang ditampilkan pada Gambar 8 merupakan tahap awal untuk menuju ke semua form yang tersedia. Ukuran layar pada halaman utama ini dibuat full screen karena sebagai pembuka dari sistem, di mana ditampilkan ikon semua menu yang ada di sistem.

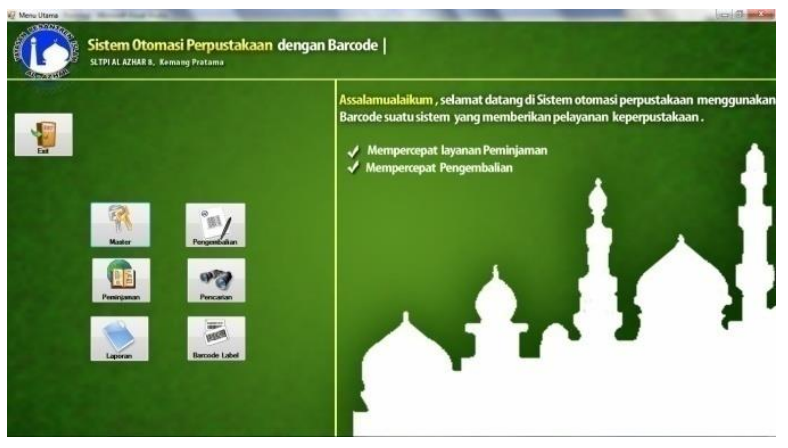

Gambar 8. Tampilan Menu Utama

Sistem ini dilengkapi dengan modul Data Master di mana Administrator Sistem Perpustakaan mendaftarkan segala macam data yang digunakan sebagai referensi yang dibutuhkan untuk menjalankan Sistem Perpustakaan, seperti Data Siswa Aktif, Data Klasifikasi, dan Data Penerbit.

Seluruh data referensi harus terdaftar secara akurat dan kemutakhirannya harus selalu dijaga agar sistem dapat berjalan dengan kinerja baik.
Beberapa keuntungan dengan dikembangkannya sistem ini antara lain:

1. Mempercepat layanan dan meningkatkan akurasi (Tabel 2):

a. Sebelum adanya sistem ini pendataan buku dilaksanakan secara manual di mana petugas menuliskan data secara manual di suatu file excel sehingga tingkat kesalahan tinggi. Dengan adanya sistem ini maka dapat diterapkan standar sehingga integritas data dapat terjaga.

b. Proses pelayanan untuk peminjaman dan pengembalian buku yang tadinya memakan waktu 3-5 menit karena petugas harus menulis secara manual ke dalam file excel. Dengan adanya sistem ini maka petugas cukup melakukan scan pada barcode yang memakan waktu kurang dari 1 menit dan sistem secara otomatis akan menentukan tanggal berapa buku itu harus dikembalikan dan menghitung bila ada perhitungan denda karena keterlambatan pengembalian buku.

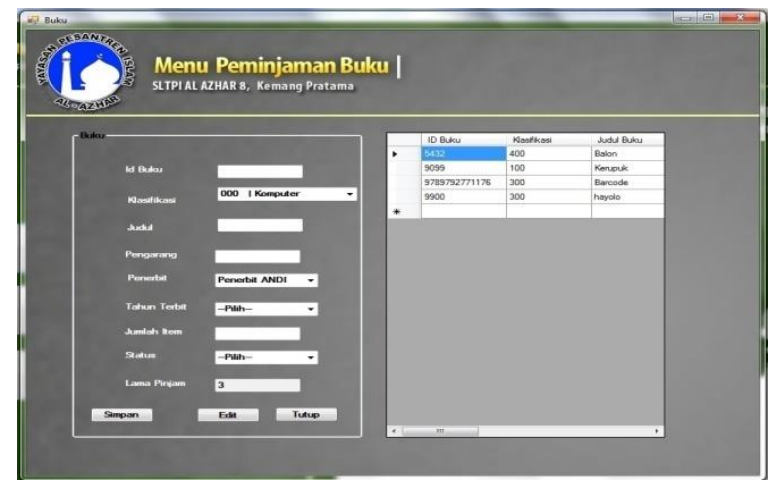

Gambar 9. Tampilan Menu Peminjaman Buku

Tabel 2. Perbandingan kondisi layanan sebelum dan sesudah ada system

\begin{tabular}{|c|c|c|c|c|c|}
\hline \multirow{2}{*}{ No } & \multirow{2}{*}{ Kegiatan } & \multicolumn{2}{|l|}{ Sebelum ada sistem } & \multicolumn{2}{|l|}{ Setelah ada sistem dengan barcode } \\
\hline & & Keterangan & Waktu & Keterangan & Waktu \\
\hline 1 & $\begin{array}{l}\text { Pendataan } \\
\text { Buku }\end{array}$ & $\begin{array}{l}\text { Penulisan kode buku secara } \\
\text { manual sehingga tingkat } \\
\text { kesalahan tinggi. }\end{array}$ & & $\begin{array}{l}\text { Penulisan kode buku dilakukan dengan } \\
\text { menggunakan sistem sehingga tingkat } \\
\text { kesalahan rendah. }\end{array}$ & \\
\hline 2 & Peminjaman & $\begin{array}{l}\text { Pencatatan kode buku, nama } \\
\text { siswa, dan lama pinjaman } \\
\text { ditulis secara manual. }\end{array}$ & $\begin{array}{c}3-5 \\
\text { menit }\end{array}$ & $\begin{array}{l}\text { Pencatatan kode buku dilakukan } \\
\text { menggunakan barcode scanner dan } \\
\text { perhitungan lama pinjam dihitung } \\
\text { otomatis oleh sistem. }\end{array}$ & 1 menit \\
\hline 3 & Pengembalian & $\begin{array}{l}\text { Pencatatan kode buku, nama } \\
\text { siswa yang mengembalikan } \\
\text { buku dan perhitungan denda } \\
\text { dilakukan secara manual. }\end{array}$ & $\begin{array}{c}3-5 \\
\text { menit }\end{array}$ & $\begin{array}{l}\text { Pencatatan kode buku, nama siswa yang } \\
\text { mengembalikan buku dilakukan } \\
\text { menggunakan barcode scanner dan } \\
\text { perhitungan denda dihitung otomatis oleh } \\
\text { sistem. }\end{array}$ & 1 menit \\
\hline
\end{tabular}


2. Pelabelan barcode pada buku:

Membantu Petugas Perpustakaan membuat label barcode untuk buku dan koleksi lain.

3. Keamanan Data:

Sistem baru menggantikan tempat penyimpanan data yang lama berupa sreadsheet yang rentan akan kehilangan data, tidak ada standar yang dapat diterapkan dan tidak terjaminnya integritas data.

\section{KESIMPULAN}

Dengan adanya sistem ini, pelayanan peminjaman, pengembalian, pendaftaran anggota baru, penambahan koleksi buku serta pelabelan buku dapat dilakukan dengan cepat dan akurat.

Sistem ini masih dapat disempurnakan dengan menerapkan sistem barcode ini untuk kartu anggota, karena saat ini kartu anggota masih dikelola secara manual dan seringkali timbul masalah karena siswa setiap tahun tentunya berubah status kelasnya.

\section{DAFTAR PUSTAKA}

[1] Sun Hong-ying, The Application of Barcode Technology in Logistics and Warehouse Management, Education Technology and Computer Science, Volume 3, halaman 732-735, ISBN: 9781-4244-3581-4, 2009.

[2] White, Gardiner, Prabhakar, and Abd Razak, A Comparison of Barcoding and RFID Technologies in Practice, Journal of Information, Information Technology, and Organizations, Volume 2, 2007.

[3] Manthou, Vlachopoulou, Bar-code technology for inventory and marketing management systems: A model for its development and implementation, International Journal of Production Economics, Volume 71, Issues 1-3, halaman 157-164, 2001.

[4] Wahyono, Teguh, Membuat Sendiri Aplikasi dengan Memanfaatkan BARCODE, Jakarta: PT Elex Media Komputindo, 2010.

[5] Pender, Thomas, UML Weekend Crash Course ${ }^{\mathrm{TM}}$, Wiley Publishing, Inc., Indianapolis, Indiana, 2002

[6] Al Fatta Hanif, Analisis dan Perancangan Sistem Informasi, Penerbit Andi, Yogyakarta, 2007. 